\title{
Reliability and Construct Validity of the Malay Version of Subjective Experience Exercise Scale (SEES) among Smokers
}

\author{
Nur-Hasanah Ruslan1, Siti Munira Yasin 2, Mohamad Rodi Isa 2, Nadzimah Mohd Nasir 2 , \\ Adjulea James ${ }^{3}$, Mohd Hamim Rajikin ${ }^{2}$ \\ ${ }^{1}$ Faculty of Sport Science and Recreation, \\ Universiti Teknologi MARA Cawangan Pahang, Bandar Pusat Jengka, 26400, Pahang Malaysia \\ 2 Faculty of Medicine, Universiti Teknologi MARA, Sg.Buloh Campus, Sg. Buloh, 47000, Selangor, Malaysia
}

${ }^{3}$ Faculty of Sport Science and Recreation, Universiti Teknologi MARA Cawangan Kota Samarahan, 94300, Sarawak, Malaysia

nur-hasanah@uitm.edu.my, smunira@uitm.edu.my, rodi@uitm.edu.my, nadzimah@uitm.edu.my, hamim400@uitm.edu.my Tel: +60179075770

\begin{abstract}
SEES is an instrument used to examine the affective state of exercise associated with mood. This study was aimed to determine the psychometric properties of Malay version. The original scale underwent forward and backward translation, cognitive debriefing and field testing. The psychometric properties were evaluated based on reliability and construct validity among 152 smokers. The translated SEES had shown satisfied reliability with Cronbach alpha of $0.80,0.73$ and 0.73 and a significant positive correlation with Profile of Mood Scale (POMS). The current study provides psychometric evidence for an appropriate, reliable and valid tool for SEES Malay version.
\end{abstract}

Keywords: Translation validation; Subjective Exercise Experience Scale; Construct validity

eISSN: 2398-42870 2020. The Authors. Published for AMER ABRA CE-Bsby e-International Publishing House, Ltd., UK. This is an open access article under the CC BYNC-ND license (http://creativecommons.org/licenses/by-nc-nd/4.0/). Peer-review under responsibility of AMER (Association of Malaysian Environment-Behaviour Researchers), ABRA (Association of Behavioural Researchers on Asians) and cE-Bs (Centre for Environment-Behaviour Studies), Faculty of Architecture, Planning \& Surveying, Universiti Teknologi MARA, Malaysia.

DOI: https://doi.org/10.21834/ebpj.v5iSl3.2572

\subsection{Introduction}

Exercise has identified as a priority area in general health promotion (U.S. Department of Health and Human Services, 1990). Generally, exercise has shown to have a mood-enhancing effect (Lane \& Lovejoy, 2001) and improve psychological well-being (Scully et al., 1998). Exercise does not only benefit the physiological aspect but also in terms of the psychological aspect as well. Subsequently, various measures have developed with the intent to assess psychological responses to the exercise stimulus. Instruments such as Profile of Mood States (POMS) and Positive and Negative Affect Schedule (PANAS) have widely used as measuring scales to measure the psychological effect of exercise.

However, those instruments have some limitations related to exercise stimulus. POMS itself was more likely to measure negative states, and the construct validity of this measure in diverse samples of exercising adults beyond the college-age is limited. Besides, the relevance of many of the items to the exercise setting is questionable (McAuley \& Courneya, 1994) whereas PANAS by Watson,

eISSN: 2398-4287@ 2020. The Authors. Published for AMER ABRA cE-Bsby e-International Publishing House, Ltd., UK. This is an open access article under the CC BYNC-ND license (http://creativecommons.org/licenses/by-nc-nd/4.0/). Peer-review under responsibility of AMER (Association of Malaysian Environment-Behaviour Researchers), ABRA (Association of Behavioural Researchers on Asians) and cE-Bs (Centre for Environment-Behaviour Studies), Faculty of Architecture, Planning \& Surveying, Universiti Teknologi MARA, Malaysia. DOI: https://doi.org/10.21834/ebpj.v5iSI3.2572 
Clark, and Tellegan (1988) comprises two 10-item mood scales adequately reflect the negative and positive effects. PANAS has reported having adequate psychometric properties and data to support the relationship between self-reported physical activities. However, PANAS employs items of questionable relevance to the stimulus properties of exercise (McAuley \& Courneya, 1994).

Subsequently, a new instrument was developed by McAuley and Courneya (1994), which is the specific measured psychological aspects of exercise stimulus. This instrument consists of 12 items with three constructs, namely, Psychological Well-Being (PWB), Psychological Distress (PD), and Fatigue (FAT). Each construct consists of 4 items. The scale rating is using a seven-point Likert scale (1=not at all, 4=moderately and 7=very) with a Likert scale ranging from 1 to 7 . SEES was widely used in exercise study (Ivancic \& Miletic, 2016; Sealey, 2010) as well as an exercise-related study (Everson, Daley \& Ussher, 2006). Recently there is no Malay translated version of SEES available. Also, currently, only one instrument is available to assess the mood in Malay which is Brunel Mood Scale (BRUMS) or POMS 2 translated and validated by Hashim, Zulkifli, and Yusof (2010) as well as Lan, Lane, Roy, and Hanin (2012). The available instrument consists of 24 items indicating the mood profile. However, some of them were less related to exercise-related feelings, for instance, item 22 (tempered) and item 24 (uncertain). With these drawbacks, the SEES translated into Malay is much required to assess the psychological aspects of exercise stimulus. In this study, we aim to determine the validity and reliability of the translated version of the SEES

\subsection{Method}

The study design is a cross-sectional study that was conducted in 13 centres, including hospitals, clinics, a training centre, and public universities. The participants recruited using convenience and snowball sampling methods. The sample size used is based on the participant's per item ratio ( $\mathrm{N}: \mathrm{p})$. In this study, a 10:1 item per participant ratio was used, which is the most recommended ratio (Tabachnick \& Fidell, 2001), and the adequate sample for conducting the factor analysis achieved (Hair et al., 2010). Since the original SEES consists of 12 items, the minimal sample required was 120 participants.

Ethical approval. This study obtained approval from the Universiti Teknologi MARA, Ethical Committee. Before the commencement of this study, written consents were provided and signed by the participants to ensure their details were kept confidential. The researchers briefed the participants on the criteria and the purpose of the study to all the participants. The final version of the SEES was distributed and self-administered to daily smokers from 13 different centres.

Instruments. The instruments used were: 1) sociodemographic questionnaire and 2) SEES questionnaire. The sociodemographic questionnaire measured age, educational level, marital status, job categories, and smoking characteristics. 2) The Malay version of SEES comprised of 12 items 3) Malay Profile of Mood States 2nd Edition (POMS) comprised of 24 items.

Translation validation process. The translation validation process conducted according to the standard guidelines (Wild et al., 2005). This study divided into three phases (see Figure 1). The details of each phase explained below.

Phase 1: Translation phase. Forward translation: The forward translation phase consisted of a forward translation of the original SEES questionnaire by McAuley and Courneya, (1994) from English (source language) to the Malay version (target language). This translation performed by two translators, who are familiar with the Anglophone culture, but their native language is Malay. Forward translation for SEES involved two translators who were F1 and F2. Both translators were qualified translators from University Malaya and Institute Terjemahan Buku Malaysia (ITBM). Backward translation also performed by a certified translator who is a qualified English expert. Reconciliation: The reconciliation process produced two versions of the Malay translation. Both versions compared by members of the research team to identify the discrepancies and ambiguities in the words and sentences of the translated version. This process aimed to produce the best translation of the original context. Then, the harmonization process performed by two panels involving members from the research team. In this process, the backward version compared to the original version. Finally, the prefinal version produced.

Phase 2: Face validity. Phase two of the study investigated the face validity by distributing the pre-final version of the questionnaire to the target population for the face value evaluation. During this phase, ten smokers underwent cognitively debriefed. Ten respondents are sufficient for pilot testing using an interview type of pilot testing (Eremenco, 2005). The respondents were Malaysian smokers whose first language was Malay. The respondents were also daily smokers. The respondents were interviewed and asked to identify words or sentences that they did not understand. The respondents were encouraged to suggest suitable alternate words with which they were familiar. Then, the feedback from this cognitive debriefing discussed among the two panels in the research team, and the final version of SEES produced.

Phase 3: Field testing and psychometric analysis. The final phase involved field testing and psychometric analysis. This phase conducted by the distribution of the final version of the questionnaire to the target population. This phase conducted to determine the reliability, construct validity, and concurrent validity.

Statistical analysis. The demographic data analyzed by descriptive statistics. The reliability of the questionnaire determined by internal consistency (Cronbach's alpha), Spearman's correlation coefficient, and the interclass correlation coefficient (ICCs). Besides, the stability of the instrument across the time assessed by test-retest reliability. For construct validity, the quality of the item assessed using factor analysis The EFA performed using principal axis factoring (PAF) extraction and oblique rotation (Promax) method (Tabachnick \& Fidell, 2001). The PAF was selected because it was the best choice for non-distribution data (Beavers et al., 2013; Costello \& Osborne, 2005) and is unlikely to produce more cross-loadings (Beavers et al., 2013). The concurrent validity was measured using the Spearman Correlation Coefficient to determine the correlation between SEES and POMs. All the statistical analysis was conducted using IBM SPSS version 23.0. 


\subsection{Result}

The result of this study was divided into descriptive statistics of the participant's characteristics, reliability, and construct validity. The construct validity reported as a) Exploratory factor analysis (EFA) and b) concurrent validity.

i) Participant characteristics. The characteristics of the 152 male smokers shown in Table 1. The mean age of the study population was $25.53 \pm 8.5$ years. The highest proportion in this sample was Malay $91.4 \%(n=139)$ and others $9.8 \%(n=10)$. Most smokers in this study were single $65.1 \%(n=99)$, married $33.6 \%(n=51)$ and widowers $1.3 \%(n=2)$. The smokers education levels were as follows: completed primary $4.6 \%(n=7)$ or secondary $68.4 \%(n=104)$ school, certificate holders $5.3 \%(n=8)$ or had a university-level education $21.7 \%$ ( $n=33$ ). For job categories, most of participants were students $59.9 \%$ ( $n=91$ ), government staff $26.3 \%$ ( $n=40)$, private staff $9.2 \%$ $(n=14)$, self-employment $3.9 \%(n=6)$ and unemployment $0.7 \%(n=0.7 \%)$. Regarding the smoking-related characteristics, the mean number of cigarettes smoked per day was $11.67 \pm 8.1$. Of the participants, $34.9 \%(n=53)$ were in the pre-contemplation stage, $45.4 \%$ $(n=69)$ were in the contemplation stage, and $18.4 \%(n=28)$ were in the preparation stage.

Table 1 : Participants characteristics for SEES study

\begin{tabular}{|c|c|c|}
\hline & mean $\pm S D$ & $\mathrm{~N}(\%)$ \\
\hline Age, mean $\pm S D$ & $25.53 \pm 8.5$ & $17-51$ \\
\hline Race n (\%) & & \\
\hline Malay & & 139(91.4) \\
\hline Others & & $10(9.8)$ \\
\hline \multicolumn{3}{|l|}{ Marital status n (\%) } \\
\hline Single & & $99(65.1)$ \\
\hline Married & & $51(33.6)$ \\
\hline Widower & & $2(1.3)$ \\
\hline \multicolumn{3}{|l|}{ Educational level $\mathrm{n}(\%)$} \\
\hline Primary & & $7(4.6)$ \\
\hline Secondary & & $104(68.4)$ \\
\hline Certificate & & $8(5.3)$ \\
\hline University & & $33(21.7)$ \\
\hline No. of cigarette per day, mean \pm SD & $11.67 \pm 8.1$ & $1-30$ \\
\hline FTND Score & $3.24 \pm 2.2$ & $0-8$ \\
\hline \multicolumn{3}{|l|}{ Stage of change $n(\%)$} \\
\hline Pre-contemplation & $53(34.9)$ & \\
\hline Contemplation & $69(45.4)$ & \\
\hline Preparation & $28(18.4)$ & \\
\hline
\end{tabular}

ii) Reliability analysis. The reliability analysis results shown in Table 2 . The reliability of an instrument is critical to determine the repeatability and consistency of the measurement. In this study, the reliability of the instrument was estimated by Cronbach's a, ICCs, and test-retest reliability. The internal consistency with Cronbach's alpha values of $0.80,0.75$, and 0.78 for positive well-being, psychological distress, and fatigue, respectively. The inter-item reliability was consistent with ICCs with $0.70,0.73$, and 0.73 , respectively. Both Cronbach alpha and ICCs were shown to have acceptable reliability. As for the test and re-test, the correlation between test and re-test ranged from $0.49,0.42$, and 0.49 , respectively. Test-retest showed moderate correlation.

Table 2: Reliability result

\begin{tabular}{llll}
\hline Construct/ltems & Cronbach's $\alpha$ & ICCs & Test and Re-test \\
\hline $\begin{array}{l}\text { Positive well-being(PWB) } \\
\text { (PWB1, PWB4, PWB7, PWB10) }\end{array}$ & 0.80 & 0.78 & $0.59,0.28,0.53,0.54$ \\
$\begin{array}{l}\text { Psychological Distress (PD) } \\
\text { (PD2, FAT3, PD5, PD8, PD11) }\end{array}$ & 0.75 & 0.73 & ${ }^{*} 0.49$ \\
Fatigue (FAT) & & & $0.45,0.29,0.38,0.48,0.50$ \\
(FAT6, FAT9, FAT12) & 0.78 & 0.73 & ${ }^{*} 0.42$ \\
\hline
\end{tabular}

${ }^{*}$ Average correlation, ICC=interclass correlation

iii) Construct validity. The construct validity assessed by factor analysis. The loading of each item was as shown in Table 3 . All the factor loading showed an acceptable value (0.40), indicating a good correlation between items and its constructs. This construct validity conducted using PAF with oblique rotation. This study has shown that the KMO measure of sampling adequacy, which was higher than $0.50(0.79)$, and Bartlett's test of sphericity was significant $(p<0.001)$. The results of the eligibility test indicated that these data were suitable for factor analysis. The communalities (extraction) of all items were satisfied and ranged from 0.30-0.69. The communalities for all each item was practically acceptable (Arifin, 2015). The communalities should remove when it is as low as 0.20 , as suggested by Child, 2006 (Samuels, 2016). Low communality indicates that the low variation in an item is explained by the construct, and the standard error is allowed to occur (Hair et al., 2014). 
Table 3: Obliquely rotated pattern matrix for SEES items

\begin{tabular}{|c|c|c|c|}
\hline Items & Positive well-being & Psychological Distress & Fatigue \\
\hline PWB_1 & 0.715 & & \\
\hline PWB_4 & 0.716 & & \\
\hline PWB_7 & 0.823 & & \\
\hline PWB_10 & 0.592 & & \\
\hline PD_2 & & 0.505 & \\
\hline FAT_3 & & 0.528 & \\
\hline PD_s & & 0.762 & \\
\hline PD_8 & & 0.602 & \\
\hline PD_11 & & 0.461 & \\
\hline FAT̄_6 & & & 0.700 \\
\hline FAT_9 & & & 0.456 \\
\hline FAT_12 & & & 0.900 \\
\hline
\end{tabular}

*Bold the item from others construct

For the data extraction factor, a scree plot extracted through three constructs. It was supported by the Kaiser Criteria, which also showed three constructs with an Eigenvalue of more than 1. That three constructs were showed that it represented 61.78 of the cumulative percentage of initial eigenvalue. The pattern matrix showed the factor loading of each item in its construct. Factor loading indicated the correlation of each item with its constructs. Each item factor loading range between 0.46 and 0.90 , and it was acceptable because it was more than 0.32 (Tabachnick \& Fidell, 2001). Ideally, the factor loading should be 0.5 (Hair et al., 2010), although above 0.3 is commonly used in EFA (Arifin, 2015). This study also has no cross-loading. The cross-loading indicated that the questionnaire had a large factor loading onto multiple factors (Matsunaga, 2011). Overall the factor analysis showed satisfied factor loading, indicating an adequate correlation between items and factors.

iv) Concurrent validity. The results of concurrent validity between SEES and POMS have shown in Table 4. The correlation assessed between three constructs in SEES and six constructs in POMS. Table 4 shows that there is a significant correlation between SEES construct and POMS except for psychological distress and tension. The correlation ranged from weak to moderate $(r=0.3-0.4)$. The concurrent validity conducted by comparing the score of the standard instrument (POMS) with a new development instrument SEES.

The measurement aims to know whether both questions measure the same construct. As expected, both instruments show a significant correlation with their related factors except Psychological Distress in SEES and Tension in POMS (Table 4). However, the strength of the correlation ranged from weak to moderate correlation r>0.3-0.4(Evans, 1996). Only one factor which is SEES-PD and POMS-tension has shown no significant correlation. Thus, this concurrent validity also indicates that POMS and SEES have similar constructs.

Table 4: Concurrent validity between SEES and POMS

\begin{tabular}{|c|c|c|c|c|c|c|}
\hline Constructs & POMS-Vigour & POMS-Anger & POMS-Confusion & $\begin{array}{l}\text { POMS- } \\
\text { Depression }\end{array}$ & POMS-Tension & POMS-Fatigue \\
\hline $\begin{array}{l}\text { SEES-positive } \\
\text { well-being }\end{array}$ & $\begin{array}{l}0.40 \\
{ }^{* *} P<0.001\end{array}$ & & & & & \\
\hline $\begin{array}{l}\text { SEES- } \\
\text { psychological } \\
\text { distress }\end{array}$ & & $\begin{array}{l}0.30 \\
{ }^{*} P<0.001\end{array}$ & $\begin{array}{l}0.30 \\
{ }^{* *} P<0.001\end{array}$ & $\begin{array}{l}0.30 \\
{ }^{*} P<0.05\end{array}$ & $\begin{array}{l}0.20 \\
P<0.127\end{array}$ & \\
\hline SEES-Fatigue & & & & & & $\begin{array}{l}0.30 \\
{ }^{*} \mathrm{P}<0.05\end{array}$ \\
\hline
\end{tabular}

${ }^{* *} P<0.001$ (highly significant), ${ }^{*} P<0.05$ (significant)

Table 5 shows the additional loading on the Psychological Distress of SEES Malay version, and fatigue contains fewer items compared to the original version.

Table 5: Factor analysis for Subjective Exercise Experience Scale $(n=152)$

\begin{tabular}{lllll}
\hline $\begin{array}{l}\text { Item } \\
\text { no. }\end{array}$ & Original Construct & Original items & Translated items & Factor loading \\
\hline 1 & PWB & Great & Hebat & 0.718 \\
2 & PD & Awful & Teruk & 0.505 \\
3 & PD & Drained & Lemah & 0.528 \\
4 & PWB & Positive & Positif & 0.716 \\
5 & PD & Crummy & Selekeh & 0.762 \\
6 & FAT & Exhausted & Letih & 0.700 \\
7 & PWB & Strong & Kuat & 0.823 \\
8 & PD & Discouraged & Tawar hati & 0.602 \\
9 & FAT & Fatigued & Lesu & 0.456 \\
10 & PWB & Terrific & Seronok & 0.592
\end{tabular}




\begin{tabular}{|c|c|c|c|c|}
\hline 11 & PD & Miserable & Sengsara & 0.461 \\
\hline 12 & FAT & Tired & Penat & 0.900 \\
\hline
\end{tabular}

\subsection{Discussion}

To the best of our knowledge, this is the first study to translate and validate the SEES questionnaire in Malay. This questionnaire underwent an extensive translation and cultural adaptation according to the standard guidelines suggested by Wild et al. (2005) to ensure the reliability and validity of the questionnaire. Besides, it had undergone extensive translation validation processes, including reverse forward and backward translation due to error in the translation processes (Ruslan et al., 2016).

Based on our study, we found that SEES for the Malay version has similar numbers of items and constructs with an original version. The EFA showed an acceptable factor loading range from and acceptable commonalities. There was acceptable factor loading because of all the items highly correlated with their constructs; similar to the commonalities. For this present study, all items shown practically acceptable communalities (>0.25) (Arifin, 2015). Thus, all 12 items decided to retain in the questionnaires. The factor analysis revealed three constructs which were Positive well-being, Psychological Distress, and fatigue. Altogether they explain $61.7 \%$ of the variance of the entire questionnaire, and it indicated high construct validity. The SEES Malay version consists of four items of PWB which were Hebat, Positif, Kuat, Seronok, five items Psychological Distress which were Teruk, Selekeh, Tawar Hati and Sengsara, Letih and three items for Fatigue which were Letih, Lesu and Penat compared to the original version consisting of four items for each construct.

Interestingly, this study found that the Malay version of the SEES was grouped similar to the original version except for item 3 from the Fatigue construct (refer to Table 6). Item 3 is Drained; it translated as Lemah in Malay. In this study, drained was perceived as physiological distress by Malaysian smokers rather than fatigued (original construct). Generally, it was acceptable to be perceived as drained (Lemah) under psychological distress because sometimes people were perceived as drained (Lemah). Drained, when perceived as psychological distress, indicates the extended effects of being drained. We suspect that in this study, participants put more intensity and severity on drained (Lemah). In general, the distress defined as "a non-specific, biological or emotional response to a demand or stressor that is harmful to the individual" (Ridner, 2004).

However, symptom distress defined as the degree of physical or mental upset caused by a specific symptom, such as fatigue, whereas symptoms of distress are subjective perceptions of the global stress response (Rhodes \& Watson 1987 cited in Ridner, 2004). In fact, by definition, psychological distress is related to fatigue. Thus, we speculated that the definition explained why drained items loaded on Psychological Distress. However, the finding of this present study cannot be compared to other study findings because there is no translation done for this instrument except translated into the Punjabi language. However, the findings of the Punjabi translation have not published yet.

The reliability of the SEES Malay is acceptable with Cronbach's alpha above 0.70 (Leech et al., 2005) and the evidence of high homogeneity among the item in the scale shown ( $\mathrm{Ng}$ et al., 2014). The original version of the SEES questionnaire by McAuley and Courneya (1994) had Cronbach's alpha values of PWB $\alpha=0.86, P D a=0.85$, and $\alpha=0.88$, respectively. Both Malay and original version internal consistency we did not look different. For stability across time, the ICCs with Two-Way Mixed and absolute agreement had indicated a moderate to excellent reliability (0.73-0.77) (Koo \& Li, 2016). The consistency of the questionnaire proved by test-retest reliability ranged between weak to moderate correlation (0.28-0.59) (Hall, 2015). Overall, this study showed satisfactory reliability and acceptable consistency.

\subsection{Conclusion and recommendations}

In summary, our translation and validation of the SEES provided satisfactory evidence of psychometric properties with acceptable reliability and validity. This Malay version of the SEES was considered valid and reliable for the Malaysian population. Future studies might be necessary to validate the SEES in a more diverse sample.

Although our study has shown satisfactory evidence of reliability and validity, some limitations identified in this study, one of the restrictions was the various participant's physical activity status (active and sedentary). Thus, the perception of exercise might be different. Secondly, the participants were only limited to smokers and did not include non-smoking participants. In general, this instrument should be tested among physically active people or athlete to assess their subjective feeling of exercise Finally, other than this limitation, and the study also has its strengths because it was conducted by considering both internal and external validity. The internal validity strengthened by controlling the characteristic of the participants, which is only smokers included in this study. Secondly, the questionnaire used underwent extensive translation and influenced the good outcome of our statistical result, whereas the external validity achieved by adequate sample size.

\section{Acknowledgements}

This study supported by a research grant Fundamental Research Gran Scheme (FRGS-5/3(124/2015). We wish to express our gratitude to all participants for their kindness and cooperation. Also, those who were involved, either directly or indirectly, throughout this study. We would like to thank the Director of the Ministry of Health, Malaysia, for allowing us to conduct this research in their facilities. 


\section{References}

Arifin, W. N. (2015). Performing EFA and reliability analysis. Retrieved from http://www.medic.usm.my/biostat/images/files/ips\%20intermediate\%202015/Performing_EFA_Cronbachs_alpha_-_IPS.pdf

Beavers, A. S., Lounsbury, J. W., Richards, J. K., Huck, S. W., Skolits, G. J., \& Esquivel, S. L. (2013). Practical considerations for using exploratory factor analysis in educational research. Practical Assessment, Research and Evaluation, 18(6), 1-13.

Costello, A. B., \& Osborne, J. W. (2005). Best practices in exploratory factor analysis: Four recommendations for getting the most from your analysis. Practical Assessment, Research and Evaluation, 10(7), 1-9. https://doi.org/10.1.1.110.9154

Eremenco, S. L. (2005). A comprehensive method for the translation and cross-cultural validation of health status questionnaires. Evaluation and the Health Professions, 28(2), 212-232. https://doi.org/10.1177/0163278705275342

Evans, J. D. (1996). Straightforward statistics for the behavioural sciences. Brooks/Cole.

Everson, E. S., Daley, A. J., \& Ussher, M. (2006). Does exercise have an acute effect on the desire to smoke, mood and withdrawal symptoms in abstaining adolescent smokers? Addict Behaviors, 31,1547-1558. https://doi.org/10.1016/j.addbeh.2005.11.007

Hair, Joseph F, Jr. G. Tomas M. Hult, Christian M Ringle, M. S. (2014). A Primer on Partial Least Squares Structure Equation Modeling (PLS-SEM). SAGE.

Hair, J. F., Black, W. C., Babin, B. J., \& Anderson, R. E. (2010). Multivariate data analysis (7th ed.). New Jersey, NJ: Pearson. https://doi.org/10.1016/j.jpharm.2011.02.019

Hall, G. (2015). Pearson's correlation coefficient, 1, 1-4. https://doi.org/10.1136/bmj.e4483

Hashim, H. A., Zulkifli, E. Z., \& Yusof, H. A. (2010). Factorial validation of Malaysian adapted Brunel Mood Scale in an adolescent sample. Asian Journal of Sports Medicine, 1, 185

Ivancic, N., Miletic, D., A. K. (2016). Research in physical education. Sport and Health 2016, 5(1), 29-32.

Koo, T. K., \& Li, M. Y. (2016). A guideline of selecting and reporting intraclass correlation coefficients for reliability research. Journal of Chiropractic Medicine, 15(2), 155-163. https://doi.org/10.1016/j.jcm.2016.02.012

Lan, M. F., Lane, A. M., Roy, J., \& Hanin, N. A. (2012). Validity of the Brunel mood scale for use with Malaysian athletes. Journal of Sports Science and Medicine, 11(1), 131-135.

Lane, A. M., \& Lovejoy, D. J. (2001). The effects of exercise on mood changes: The moderating effect of depressed mood. Journal of Sports Medicine and Fitness, 41(4), 539-545.

Leech, N. L., Barrett, K. C., \& Morgan, G. A. (2005). SPSS for Intermediate Statistics use and interpretation (2nd ed.). New Jersey and London: Psychology Press. https://doi.org/10.1017/CB09781107415324.004

Matsunaga, M. (2011). How to factor-analyze your data right: Do's, don'ts, and how-to's. International Journal of Psychological Research, 3(1), 97-110. https://doi.org/10.4090/juee.2008.v2n2.033040

McAuley, E., \& Courneya, K. S. (1994). The subjective exercise experiences scale (SEES): Development and preliminary validation. Journal of Sport and Exercise Psychology, 16, 163.

Ng, C. G., Chin, S. C., Yee, A., Loh, H. S., Sulaiman, A. H., Wong, S. S. K., \& Habil, M. H. (2014). Hamilton pleasure scale: Comparison between depressed patients and healthy subjects at an out-patient clinic in Malaysia. The Malaysian Journal of Medical Sciences, 21(3), 62-70.

Nur Hasanah Ruslan, Siti Munira Yasin, Nooni Ezdiani Yasin, \& Rokiah Awang. (2016). Detection of translation error during cognitive debriefing and exploratory factor analysis of Subjective Experience Exercise Scale (SEES) translation Process. Proceeding Seminar Interpretasi dan Terjemahan, October, 186-193.

Ridner, S. H. (2004). Psychological distress: Concept analysis. Journal of Advance Nursing, 45(5), 536-45.

Samuels, P. (2016). Advice on exploratory factor analysis (June). https://doi.org/10.13140/RG.2.1.5013.9766

Sealey, R. M. (2010). Acute exercise in Vietnam Veterans is Associated with positive subjective experiences. International Journal of Exercise Science, 3(1), 36-42. Retrieved from http://ezproxy.library.usyd.edu.au/login?url=http://search.ebscohost.com/login.aspx?direct=true\&db=sph\&AN=53495271\&site=ehost-live

Tabachnick, B. G., \& Fidell, L. S. (2001). Using multivariate statistics (5th ed.). Needham Height, MA: Allyn \& Bacon.

Watson, D., Clark, L. A., \& Tellegan, A. (1988). Development and validation of brief measures of positive and negative affect: The PANAS scales. Journal of Personality and Social Psychology, 54, 1063-1070

Wild, D., Grove, A., Martin, M., Eremenco, S., McElroy S., Verjee-Lorenz, A., \& Erikso, P. (2005). Principles of good practice for the translation and cultural adaptation process for Patient-Reported Outcomes (PRO) measures. Value in Health, 8(2), 95-104. 